\title{
PERANCANGAN SISTEM INFORMASI BERBASIS ORIENTASI OBJEK MENGGUNAKAN STAR UML DI CV NIASA BANDUNG
}

\author{
Nova Indrayana Yusman \\ STKOM AL-MA'SOEM \\ novaindrayana@yahoo.com
}

\begin{abstract}
In terms of data processing information, in NIASA CV there is no permanent system yet, did not use any application like Microsoft Excel and others. For the size of a company, according to the author's observations there are many weaknesses, and the system used so far is only the result of the calculation of the purchase of raw materials and the sale of finished goods. The report also took a long time to record it because there is no bookkeeping.

In this design system using the method of survey in the collection and processing of data information to contain a picture of the situation in place of research object. As for system design, the author uses Unified Modeling Language (UML). UML it self are one of many tools under Object Oriented Programming, so safe to assume that Star UML will be the right tool for analyze. The design is now expected to facilitate users in reporting and the owners of Niasa $C V$ can view or collect reports easily, quickly, and probably help the CV to have a permanent system.
\end{abstract}

Keyword : Information System, Survey, Unified Modeling Language, Star UML, Object Oriented Programming.

\begin{abstract}
ABSTRAK
Dalam hal pengolahan data informasi, di CV Niasa masih belum ada sistem permanen. Untuk ukuran sebuah perusahaan, menurut pengamatan penulis ada banyak kelemahan, dan sistem yang digunakan selama ini hanyalah hasil dari perhitungan struk pembelian bahan baku dan penjualan barang jadi. Laporan pun membutuhkan waktu lama untuk membukukannya karena tidak ada pembukuan.

Dalam sistem ini perancangan menggunakan metode survey dalam pengumpulan dan pengolahan data informasi untuk memuat gambaran mengenai situasi di tempat objek penelitian. Sedangkan untuk perancangan sistem, penulis menggunakan UML (Unified Modeling Language). UML sendiri termasuk salah satu bahasan di dalam pemograman berorientasi objek (OOP), maka diambilah Star UML sebagai alat untuk melakukan analisa. Perancangan yang dilakukan sekarang diharapkan memudahkan para pengguna dalam pencentakan laporan dan para pemilik di CV Niasa dapat melihat atau menggambil laporan dengan mudah, cepat, dan mungkin bisa membantu perusahaan mempunyai sistem permanen.
\end{abstract}

Kata kunci : Sistem Informasi, Survei, Star UML, Unified Modeling Language, OOP.

\section{PENDAHULUAN}

\subsection{Latar Belakang Masalah}

CV Niasa yang beralamat di Jalan Kacapiring No 73/122 Bandung 40271 merupakan salah satu industri rumahan yang bergerak dalam bidang pangan, tepatnya pembuatan kue kering dan cokelat. Perusahaan ini mempunyai 5 orang manajerial dan 30 orang pegawai. Dalam pengolahan datanya masih memakai pendekatan klasik dan perhitungan kira-kira, sehingga masih banyak kendala yang dihadapi. Beberapa tahun belakangan ini, telah terjadi penggelapan uang besar-besaran oleh karyawan di CV Niasa, dikarenakan tidak ada sistem yang mengawasi. Untuk sebuah perusahaan yang sudah masuk golongan $\mathrm{CV}$ pun, perusahaan 
ini membuat laporan akhir hanya berdasarkan struk transaksi pembelian bahan baku dan penjualan barang jadi tanpa adanya penulisan laporan mingguan atau bulanan.

Berdasarkan permasalahan diatas, maka penulis tertarik untuk mengambil judul "Perancangan Sistem Informasi Berbasis Orientasi Objek dengan Menggunakan Star UML di CV Niasa Bandung".

\subsection{Identifikasi Masalah}

Pada penyajian sistem infomasi yang digunakan di CV NIASA memiliki kelemahankelemahan, diantaranya yaitu :

1. Sistem belum terintregerasi dengan baik.

2. Penyajian data dan laporan yang memakan waktu lama.

3. Sangat beresiko terjadinya duplikasi, kekurangan, dan terhapusnya data.

\section{METODOLOGI}

\subsection{Metode Penelitian}

Dalam proses pengumpulan data, penulis menggunakan metode deskriptif dalam mendapatkan informasi yang sesuai dengan kebutuhan penulisan. Metode deskriptif adalah metode yang menggambarkan objek yang sesuai dengan kenyataan. Dalam hal ini metode yang dilakukan adalah dengan cara survey.

Menurut Sendjaja mengemukakan bahwa "survey menunjukan adanya pengaruh daya tarik". Adapun teknik pengumpulan data untuk survey yang dilakukan penulis, adalah:

1. Observasi

Merupakan pengamatan yang dilakukan adalah secara langsung dalam kurun waktu yang ditentukan di CV NIASA.

2. Kuesioner

Adalah pertanyaan-pertanyaan secara tertulis dan terstruktur disiapkan oleh penulis yang kemudian dibagikan ke semua karyawan dan manajerial di CV NIASA.

3. Wawancara

Merupakan pengamatan yang dilakukan berupa menanyakan sejumlah pertanyaan ke individu-individu penting di dalam perusahaan, penulis memakai rumus slovin untuk menentukan jumlah individu yang diwawancara.

4. Studi Pustaka

Merupakan pengumpulan data yang dimaksudkan untuk mendukung penulisan secara ilmiah dan disajian panduan-panduan tertulis yang berkaitan dengan objek penelitian.

\subsection{Metode Pengembangan Sistem}

Dalam perancangan sistem ini penulis menggunakan metode Object Oriented Analysis and Design, dengan aktifitas yang berfokus pada pengembangan model dengan menggunakan bahasa Unified Model Language sebagai perangkat perancangan sistem terdiri dari use case, activity dan class diagram. Menurut Booch (2011) "UML adalah bahasa standar untuk membuat rancangan software, UML biasanya digunakan untuk membangun dokumen dari software-intensive system". UML merupakan bahasa standar yang sering kali dipakai untuk menjelaskan proses analisa dan desain sistem berorientasi objek.

Pada tahan analisa, UML sendiri mengembangkan model dari aplikasi yang ada di dunia nyata dengan memperlihatkan komponen-komponen penting yang bisa dijadikan prototipe. Pada tahap perancangan adalah bagaimana hasil analisa orientasi aplikasi direalisasikan pada lingkungan implementasi. Menurut Nugroho (2010), "UML adalah bahasa pemodelan untuk sistem untuk sistem berparadigma objek". 
UML sendiri menyediakan diagram-diagram yang dapat membantu mendefinisikan dan membagi sebuah aplikasi. Diagram-diagram tersebut dijelaskan seperti pada tabel 1 di bawah ini.

Tabel 1 Tipe Diagram UML

\begin{tabular}{|c|c|}
\hline Diagram & Deskripsi \\
\hline Use Case & $\begin{array}{l}\text { Bagaimana aktor atau user berinteraksi } \\
\text { dengan sebuah sistem }\end{array}$ \\
\hline Activity & Perilaku prosedural \\
\hline Class & Kelas, fitur, dan hubungan relasinya \\
\hline Package & Struktur hirarki \\
\hline Collaboration & $\begin{array}{l}\text { Penggambaran interaksi antar objek } \\
\text { yang menekankan peran masing-masing } \\
\text { objek }\end{array}$ \\
\hline Sequence & $\begin{array}{l}\text { Penggambaran interaksi antar objek } \\
\text { yang menekankan pada urutan }\end{array}$ \\
\hline Component & Struktur dari komponen \\
\hline Deployment & Instalasi \\
\hline
\end{tabular}

\section{ANALISA DAN PERANCANGAN SISTEM}

\subsection{Use Case Diagram}

Use case diagram digunakan untuk menggambarkan atau menjelaskan secara ringkas siapa (aktor) yang menggunakan sistem dan apa saja yang bisa dilakukannya (aktor). Menurut Whitten dan Bentley (2009) "Use case diagram adalah sebuah diagram yang mendeskripsikan interaksi antara sistem dengan bagian eksternal dari sistem serta dengan pengguna". Untuk memudahkan menjelaskan apa yang ada di dalam use case diagram, penulis menyiapkan tabel penjelasan mengenai apa-apa saja yang adanya, seperti pada tabel 2 berikut ini.

Tabel 2 Daftar Simbol Use Case Diagram

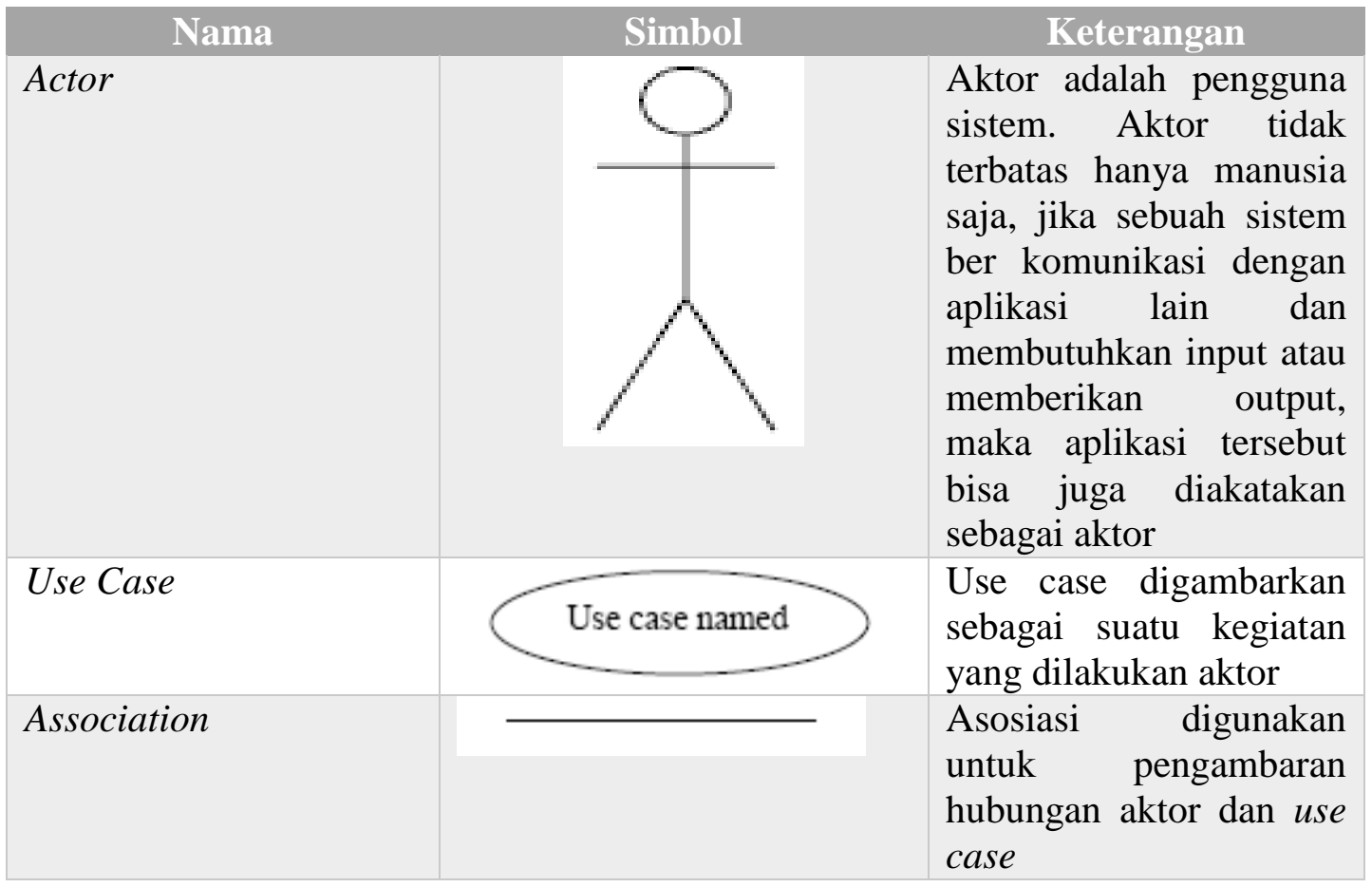


Simbol use case diagram pada tabel diatas akan dijelaskan sebagai berikut :

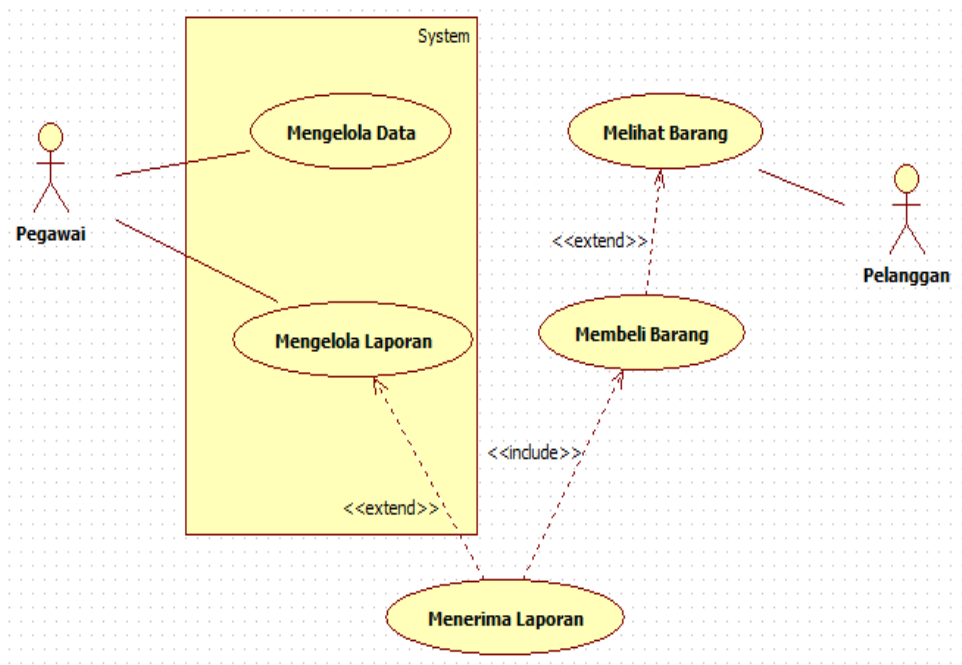

Keterangan :

Gambar 1 Use Case Diagram Transaksi

\begin{tabular}{|c|c|c|c|}
\hline Nomor & Use Case & Aktor & Keterangan \\
\hline 1 & Mengelola Data & $\begin{array}{ll}\text { Pegawai atau } \\
\text { Karyawan atau } \\
\text { Admin }\end{array}$ & $\begin{array}{l}\text { Aktor disini bisa admin atau bisa juga } \\
\text { pimpinan cabang atau pimpinan } \\
\text { perusahaan, lalu aktor bisa mengelola } \\
\text { data perusahaan baik itu data pegawai, } \\
\text { data penjualan, data pemesanan } \\
\text { ataupun data penerimaan barang. } \\
\text { Mengelola data ini didalamnya } \\
\text { termasuk tambah data, hapus data, dan } \\
\text { edit data }\end{array}$ \\
\hline 2 & $\begin{array}{l}\text { Mengelola } \\
\text { Laporan }\end{array}$ & $\begin{array}{ll}\text { Pegawai } & \text { atau } \\
\text { Karyawan } & \text { atau } \\
\text { Admin } & \end{array}$ & $\begin{array}{l}\text { Setelah mengelola data, data kemudian } \\
\text { disimpan dalam berkas atau dalam } \\
\text { database kemudian dijadikan sebagai } \\
\text { laporan, laporan ini kemudian dikelola } \\
\text { oleh aktor }\end{array}$ \\
\hline 3 & Melihat Barang & $\begin{array}{l}\text { Pelanggan atau } \\
\text { Pembeli }\end{array}$ & $\begin{array}{l}\text { Daftar barang yang ada di katalog atau } \\
\text { di etalase perusahaan dapat dilihat oleh } \\
\text { pembeli }\end{array}$ \\
\hline 4 & Membeli Barang & $\begin{array}{l}\text { Pelanggan atau } \\
\text { Pembeli }\end{array}$ & $\begin{array}{l}\text { Selain melihat barang, pelanggan atau } \\
\text { pembeli mempunyai hak membeli } \\
\text { barang }\end{array}$ \\
\hline 5 & $\begin{array}{l}\text { Menerima } \\
\text { Laporan }\end{array}$ & $\begin{array}{ll}\text { Pegawai dan } \\
\text { Pelanggan }\end{array}$ & $\begin{array}{l}\text { Use case menerima laporan adalah } \\
\text { milik ke } 2 \text { aktor, seperti aslinya } \\
\text { pelanggan ataupun pegawai menerima } \\
\text { struk hasil pembelian atau penjualan }\end{array}$ \\
\hline
\end{tabular}

\subsection{Activity Diagram}

Activity diagram adalah diagram yang menggambarkan aliran kerja, aktivitas dari sebuah sistem atau aktor atau proses bisnis. Menurut beberapa ahli, activity diagram adalah penjabaran detail dari proses use case diagram. Tabel 3 berikut ini akan menjelaskan simbolsimbol apa saja yang terdapat pada activity diagram. 


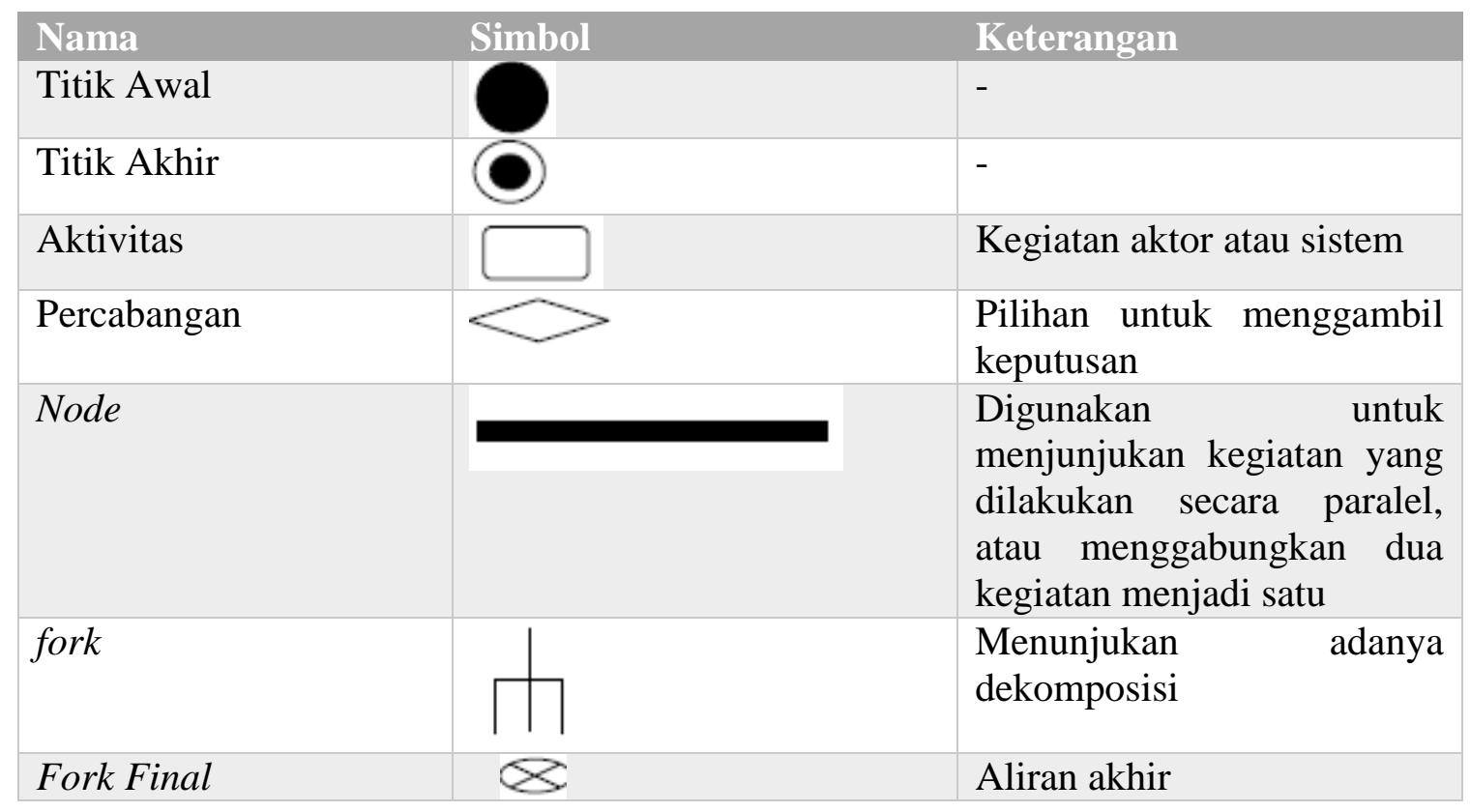

Activity diagram akan dijelaskan sebagai berikut :

1. Activity Diagram Pegawai

Seperti yang dijelaskan pada sub-bab sebelumnya, activity diagram adalah penjabaran secara detail dari use case, berikut ini adalah deskripsi activity diagram untuk tabel 4 , antara lain :
a. Pegawai membuka halaman utama ( penulis menggambarkan aktivitas dengan asumsi perusahaan sudah mempunyai web program atau desktop program ).
b. Kemudian reaksi sistem ketika pegawai membuka halam utama adalah menampilkan halaman login yang kemudian dilanjutkan dengan check id dan password pegawai.
c. Setelah id password di validasi, pegawai bisa mengelola data, dan menyimpan data yang telah diolah.
d. Data yang telah diolah kemudian dijadikan sebagai laporan yang kemudian bisa dilihat oleh karyawan dan disimpan oleh sistem.
e. Terakhir, laporan yang telah dibuat dapat di cetak untuk keperluan perusahaan. 


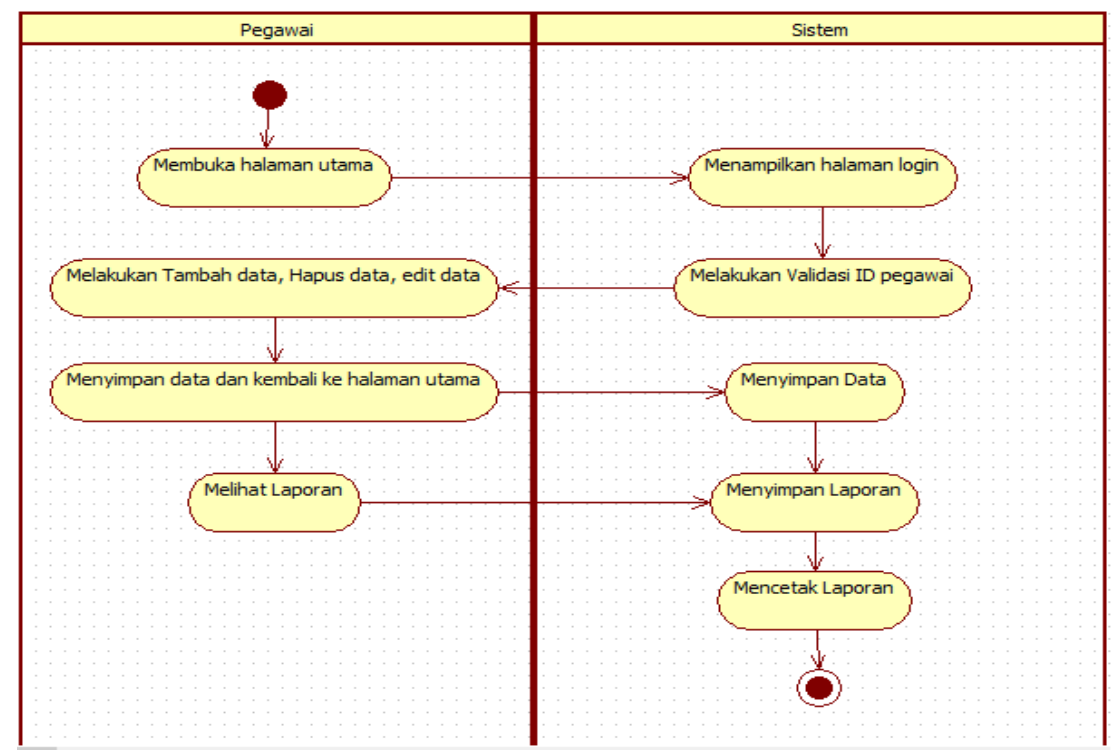

\section{Activity Diagram Pelanggan}

Pada use case bagian melihat barang dan memesan barang yang diketahui menjadi hak pelanggan, akan dijabarkan secara detail pada tabel 5 yang akan dijelaskan sebagai berikut:

a. Konsumen dapat membuka halaman utama pada program yang telah disediakan perusahaan.

b. Kemudian sistem merespon dengan membuka halam pendaftaran untuk pelanggan baru, sehingga pelanggan bisa mempunyai akses untuk melihat halaman katalog tentang produk perusahaan.

c. Pelanggan bisa menerima struk laporan ketika sudah memilih dan memesan barang.

d. Kemudian sistem merespon dengan menyimpan data barang pilihan pelanggan dan menyimpan dan mencetak laporan.

Tabel 5 Activity Diagram Pelanggan

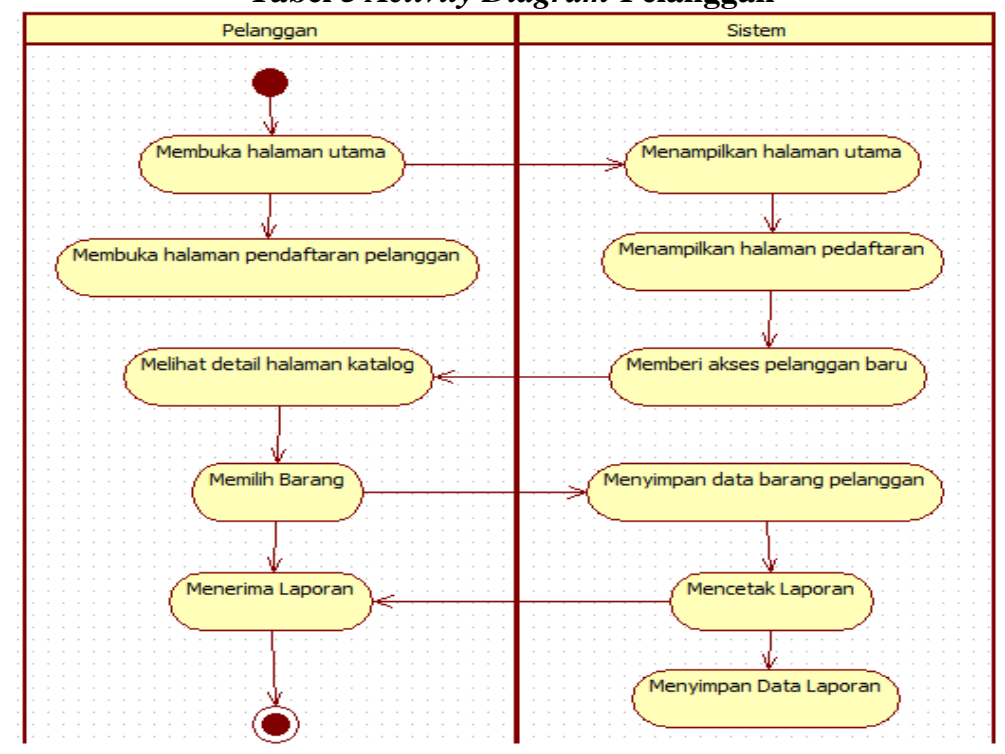

3. Activity Diagram Pencetakan Laporan 
Pada use case bagian penerimaan laporan dan pengelolaan laporan akan dijabarkan secara detail dengan activity diagram pencetakan laporan pada tabel 6 yang akan dijelaskan sebagai berikut :

a. Setiap pelanggan memesan barang ada halaman khusus untuk membuat form laporan data barang, karyawan bagian gudang adalah pemegang hak untuk mengelola laporan data.

b. Kemudian sistem akan merespon dengan meperlihatkan beberapa form laporan dan kemudian setelah dipilih langsung bisa di cetak.

c. Di bagian arsip atau database hanya ada data laporan yang dicetak saja, selebihnya tidak ada arsip apa-apa.

Tabel 6 Activity Diagram Pencetakan Laporan

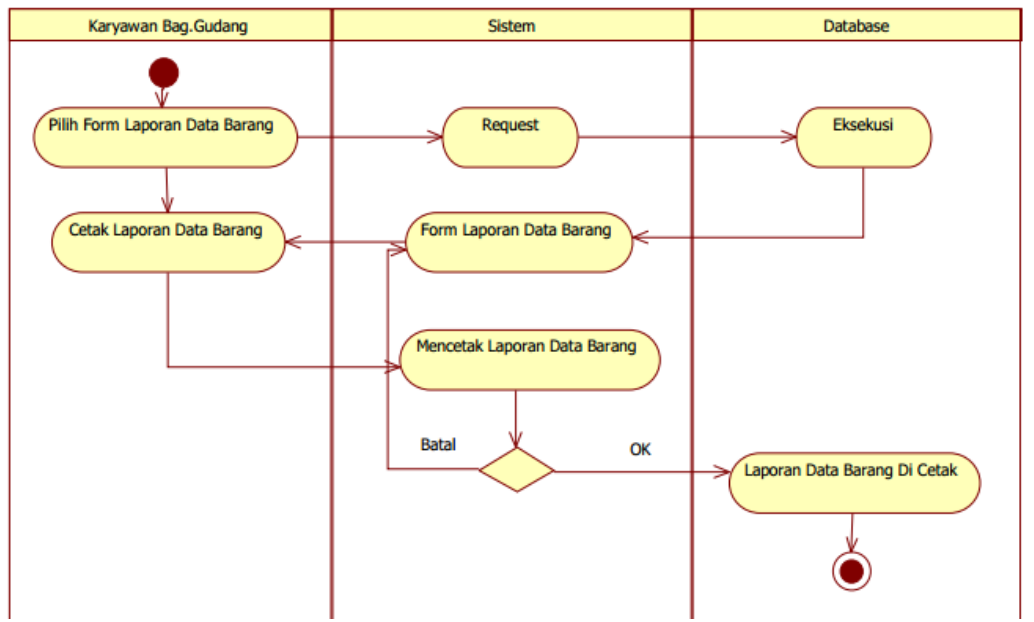

\subsection{Class Diagram}

Untuk membuat dokumen sederhana dalam perusahaan CV Niasa, penulis mencoba membuat class diagram yang nantinya bisa dibuat memakai MySQL ataupun software untuk membuat database yang lain. Pada gambar 3.7 dijabarkan secara keseluruhan class diagram yang dibuat.

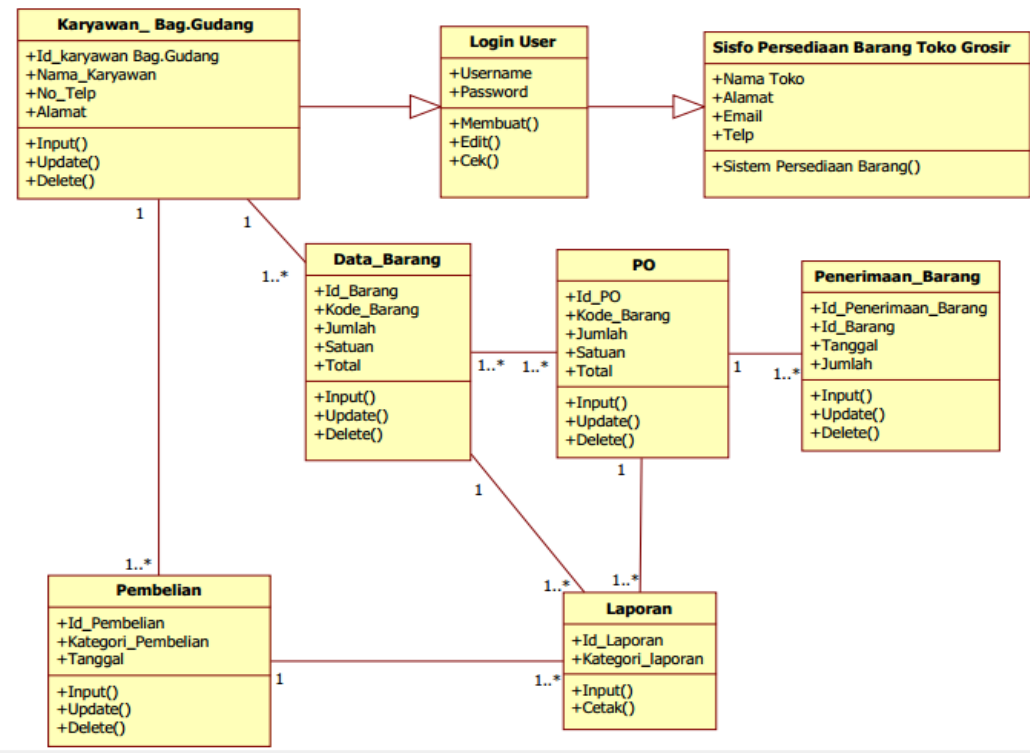

Gambar 2 Class Diagram

Class diagram adalah model yang menggambarkan struktur dan deskripsi di dalam kelas itu sendiri serta hubungan antara kelas dan kelas lain, mirip dengan diagram ER pada pemograman terstruktur dengan bedanya pada diagram ER tidak terdapat metode dan operasi 
tapi hanya ada atribut, sedangkan class diagram terdiri dari nama kelas, atribut dan metode, pada tabel di bawah ini merupakan beberapa contoh simbol di dalam class diagram.

Tabel 6 Tabel Simbol Class Diagram

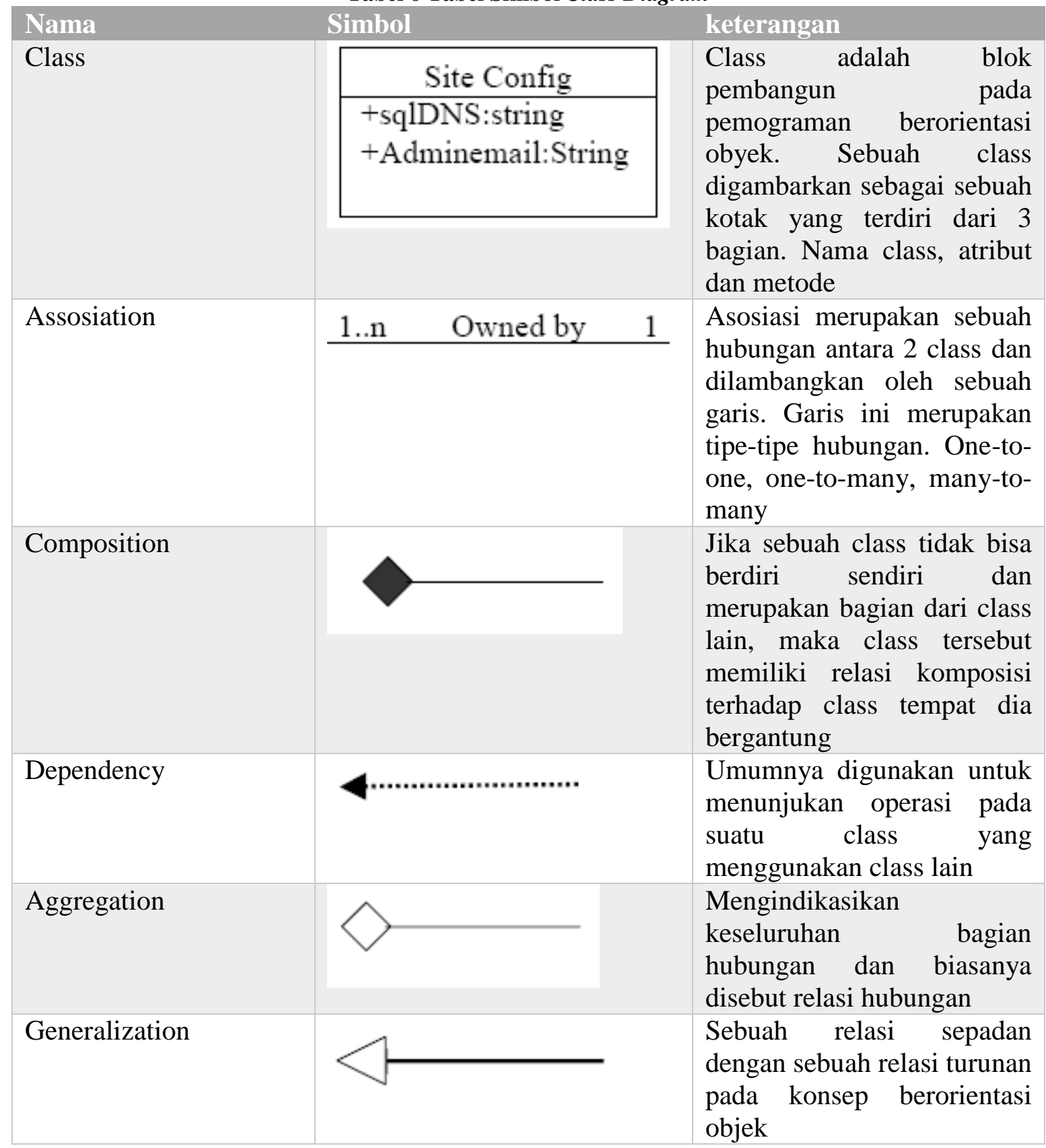

\section{PENUTUP}

\subsection{Kesimpulan}

Berdasarkan penjelasan pada sub-bab sebelum-sebelumnya, maka dapat disimpulkan beberapa tujuan, antara lain:

1. Memungkinkan data terintegrasi dalam sebuah sistem aktivitas.

2. Mempermudah penyajian data dan laporan.

3. Meminimalisir kemungkinan terjadinya duplikasi data dan terhapusnya data. 


\subsection{Saran}

Pembuatan sistem baru ini masih jauh dari kata sempurna dan masih menyisakan kekurangan, oleh karena itu penulis memberikan saran kepada peneliti selanjutnya, antara lain:

1. Diharapkan kepada pihak lembaga-lembaga memberikan syarat dan evaluasi mengenai industri rumahan agar mempunyai sistem yang mumpuni.

2. Diharapkan kepada pihak lembaga agar ikut serta dalam pengawasan setiap industri rumahan agar terjaga kualitasnya.

3. Ada sistem yang menjadi standar untuk pembentukan sistem industri rumahan.

4. Perlunya ketersediaan perangkat-perangkat pendukung seperti hardware dan software untuk menjadi pelengkap sistem.

\section{DAFTAR PUSTAKA}

Bentley, Whitten. (2009). Systems Analysis and Design Methods Editions. MA:McGraw-hill Irwin. Boston.

Booch, Grady. (2005) Object Oriented Analysis and Design 2nd Edition. Addison-Wesley Professional. New York.

Nugroho, Adi. (2010). Rekayasa Perangkat Lunak Menggunakan UML dan Java, Yogyakarta:Andi Offset.

Sendjaja, Sasa Djuarsa (1993). Teori Komunikasi. Universitas Terbuka. Jakarta.

Suhendar A, Gunadi H (2002). Visual Modeling Menggunakan UML dan Rational Rose. Informatika. Bandung.

Widodo. (2011). Menggunakan UML. Informatika. Bandung. 